Revista Brasileira de Meteorologia, v.29, n.3, 379 - 388, 2014

http://dx.doi.org/10.1590/0102-778620120439

\title{
VARIAÇÕES DA FRENTE DA GELEIRA POLAR CLUB, PENÍNSULA POTTER (ILHA REI GEORGE, ANTÁRTICA MARÍTIMA) ENTRE 1986 E 2011
}

\author{
EVERTON LUÍS POELKING ${ }^{1}$, ANDRÉ MEDEIROS DE ANDRADE ${ }^{2}$, GONÇALO BRITO T. G. \\ VIEIRA $^{3}$, CARLOS ERNESTO G. R. SCHAEFER ${ }^{4}$, ELPÍDIO INÁCIO FERNANDES FILHO ${ }^{4}$ \\ ${ }^{1}$ Universidade Federal do Recôncavo da Bahia (UFRB), Cruz das Almas, BA, Brasil \\ ${ }^{2}$ Universidade Federal do Rio Grande do Sul (UFRGS), Porto Alegre, RS, Brasil \\ ${ }^{3}$ Universidade de Lisboa (UL), Lisboa, Portugal \\ ${ }^{4}$ Universidade Federal de Viçosa (UFV), Viçosa, MG, Brasil
}

everton@ufrb.edu.br, andre.medeiros@ufrgs.br,vieira@campus.ul.pt, carlos.schaefer@ufv.br, elpidio@ufv. br

Recebido Fevereiro de 2012 - Aceito Novembro de 2013

\begin{abstract}
RESUMO
As mudanças ambientais, especialmente na criosfera, podem resultar em amplas consequências globais, sendo o estudo de geleiras das regiões polares estratégicos para analisar áreas sensíveis às mudanças climáticas. Neste trabalho foram analisadas as taxas de mudança da frente da geleira Polar Club e comparadas com a variabilidade interanual da temperatura do ar, na Península Potter, ilha Rei George, a fim de compreender o impacto direto das alterações do clima local na dinâmica das áreas livres de gelo. Foi utilizada uma série de dez cenas de imagens do satélite Landsat e dados de temperatura do ar superficial entre 1986 e 2011. Os resultados evidenciam uma tendência no aumento na temperatura do ar de $0,04{ }^{\circ} \mathrm{C}$ por ano, o que resultou no incremento de $1,03{ }^{\circ} \mathrm{C}$ nas temperaturas médias do ar para o período de 26 anos analisados. A frente da geleira ao longo dos últimos 26 anos apresentou recuo progressivo, resultando em um aumento de $1,63 \mathrm{~km}^{2}$ de área livre de gelo na Península Potter. As influências das temperaturas atmosféricas no recuo da geleira demonstraram um atraso de cerca de um ano. Apesar das evidências do aumento das temperaturas médias do ar na região, apenas a série de temperaturas atmosféricas não é suficiente para explicar essa variação observada. Este fenômeno pode estar associado à re-acomodação das tensões da camada de gelo na ilha Rei George, às mudanças nas taxas de precipitação e condições climáticas.
\end{abstract}

Palavras-Chave: Deglaciação, SIG, Mudanças climáticas.

\begin{abstract}
VARIATIONS OF THE FRONT OF POLAR CLUB GLACIER, PENINSULA POTTER, BETWEEN 1986 AND 2011

Environmental changes, especially in the cryosphere, can result in large global consequences. Studies of glaciers in the Polar Regions are strategic for analyzing climate change sensitive areas. This work analyzed the glaciers front change rates of the Polar Club and compared with inter-seasonal variability of air temperature at Potter Peninsula, King George Island, in order to understand direct impact of the climate change on the local ice-free areas dynamics. We used a series of ten Landsat satellite imagery scenes and atmospheric temperature data from 1986 to 2011. The results show an increasing trend of $0.04{ }^{\circ} \mathrm{C}$ per year, which resulted in an increment of $1.03{ }^{\circ} \mathrm{C}$ in average temperatures for the 26-year analyzed period. The front of the glacier over the past 26 years showed progressive withdrawal mapped, resulting in an increase of $1.63 \mathrm{~km}^{2}$ of ice-free area at Potter Peninsula. The influences of atmospheric temperature at the glacier's retreat demonstrate delay of about one year. Despite the evidence of increased average air temperatures in recent decades in the region, the series of atmospheric temperatures alone is not sufficient to explain the variation observed for the Polar Club glacier front. These phenomena may be associated with re-accommodation of the ice sheet stresses across King George, changes in rainfall rates and climate conditions.
\end{abstract}

Keywords: Deglaciation, GIS, Climatic changes. 


\section{INTRODUÇÃO}

A região da Antártica Marítima tem sofrido alterações em seus ecossistemas terrestres em função das recentes mudanças climáticas reportadas, destacando aquelas sofridas pelas geleiras das regiões polares (Braun e Gossmann, 2002). A temperatura média do ar na superfície do planeta aumentou $0,06{ }^{\circ} \mathrm{C}$ por década durante o século XX (Houghton et al., 2001), sendo que nos anos de 1979 a 1998 , o aumento foi de $0,19^{\circ} \mathrm{C}$ (National Research Council, 2000). A região da Península Antártica foi a que apresentou o maior aumento das temperaturas nas últimas décadas em todo planeta (Chwedorzewska, 2009), com média em torno de 2,5 ${ }^{\circ} \mathrm{C}$ desde 1945 (Vaughan et al., 2001; Kejna, 2003; Turner et al., 2005). Na Ilha Rei George, estudos apontam para uma elevação de $1,08^{\circ} \mathrm{C}$ na temperatura média entre 1945 e 1995 (Ferron et al., 2004).

A região da Antártica Marítima representa uma área de alta sensibilidade às alterações climáticas. Encontra-se em posição climática próxima do limite térmico de ocorrência de permafrost na Antártica, com temperaturas médias anuais ligeiramente inferiores a $0{ }^{\circ} \mathrm{C}$, e influência marinha (Arigony Neto et al., 2001; Braun e Gossmann, 2002; Vieira et al., 2010) (Figura 1a). Por esta razão, pequenos incrementos na temperatura podem acarretar em alterações nos ambientes com consequências ao ecossistema das áreas livres de gelo (Arigony Neto et al., 2001).

Slaymaker e Kelly (2007) alertam que o aumento das áreas livres de gelo decorrentes da alteração do clima ocasiona uma série de transformações locais, como diminuição do albedo das superfícies, fazendo com que os solos absorvam maior energia solar, o que pode afetar o microclima do solo, alterando a distribuição da cobertura vegetal e migração da fauna. Além disso, o degelo do permafrost gera alterações no regime hídrico dos solos, liberação de metano e outros gases de efeito estufa que contribuem para elevação das temperaturas no planeta. As recentes áreas livres de gelo ficam disponíveis para serem colonizadas por plantas e provêm novos habitats para fauna (Simões et al., 2004; Bremer et al., 2004; Braun e Gossmann, 2002; Convey, 2006; Andrade, et al., 2014). Esta mudança ambiental traz consequências para a biota nesta região, como alteração nas taxas de crescimento, invasão e colonização acidental de espécies exóticas trazidas pelo homem (Convey, 2006). As mudanças na circulação atmosférica nesta região afeta também os sistemas de geleiras, influenciando no balanço de massa glaciar (Braun e Gossman, 2002).

Mapeamentos obtidos por fotografias aéreas, imagens de satélites e levantamentos no campo, comprovam o processo de retração das frentes de geleiras ao longo das últimas décadas na Antártica Marítima como potencial influência das mudanças climáticas regionais (Park et al., 1998; Arigony Neto et al., 2001; Braun e Gossmann, 2002; Bremer et al., 2004). Braun e Gossmann (2002) constataram uma tendência de retração das geleiras nas ilhas Shetlands do Sul na ordem de 0,01 a 0,5 $\mathrm{km}^{2}$ por década na sua área coberta por gelo. Em toda Ilha Rei George foi detectado uma redução de $7,7 \%\left(0,36 \mathrm{~km}^{2}\right)$ na sua área de gelo (Braun et al., 2001), expondo grandes áreas de solos e sedimentos subglaciais, como consequência do aumento das temperaturas médias anuais. Birkenmajer (1998), em um mapeamento realizado em 1983, constatou que a geleira sobre a Península Potter encontrava-se em franco retrocesso. O processo de retração das geleiras em toda Ilha Rei George indicam que os parâmetros de balanço de massa das geleiras ocorreram, ou ainda estão ocorrendo (Braun e Gossmann, 2002), possivelmente como resultado do rápido aumento das temperaturas médias do ar na região nas últimas décadas (Park et al., 1998).

Este trabalho baseia-se na análise multitemporal de imagens de satélites, para identificar alterações na frente da geleira Polar Club na Península Potter, Ilha Rei George, relacionadas com as variações interanuais de temperatura médias do ar no período de 1986 a 2011, a fim de compreender o impacto direto das alterações do clima local na dinâmica das áreas livres de gelo.


Figura 1 - a) Isolinhas de temperaturas médias anuais do ar no continente antártico $\left({ }^{\circ} \mathrm{C}\right)$ (Adaptado de Braun e Gossmann, 2002). b) Localização da área de estudo. 


\section{MATERIAL E MÉTODOS}

\subsection{Caracterização da área de estudo}

A geleira Polar Club possui uma área aproximada de $28,90 \mathrm{~km}^{2}$ (Braun e Gossmann, 2002) e pertence ao campo de gelo Warsawa, com a parte sul de sua frente de geleira terminando sob a Península Potter e parte sobre o estreito de Bransfield (Figura 1b). O clima da Ilha Rei George é muito influenciado pelos movimentos dos ciclones de oeste para leste, e segundo a classificação de Köppen (1948) é de regime ET, polar tipo tundra, com temperatura atmosférica média anual de $-2,8^{\circ} \mathrm{C}$, com variações no período do verão de $-1,3$ a $2,7^{\circ} \mathrm{C}$ e no inverno de $-15,5$ a $-1,0{ }^{\circ} \mathrm{C}$ (Ferron et al., 2004). A sucessão dos centros de baixa pressão ocorrem com frequência, com a atividade dos ciclones que trazem ar mais quente e úmido do estreito de Drake, favorecendo a ocorrência de chuvas, chuviscos e neve durante o verão (Setzer et al., 2004). Essa região revela características bem marcadas de ambiente periglacial na zona litorânea, com verões curtos e temperaturas médias anuais baixas (Setzer et al., 2004). Durante o verão, devido à elevação da temperatura, é ocasionado um intenso processo de derretimento que provém abastecimento de água aos lagos e drenagens.

\subsection{Processamento das imagens de satélites}

\subsubsection{Imagens de satélites}

As imagens utilizadas no trabalho foram obtidas pela agência United States Geological Survey (USGS, 2010), totalizando dez imagens dos satélites Landsat 5 e 7, sensor TM (Thematic Mapper). A Figura 2 exibe o acervo de imagens utilizadas para delinear as taxas de variação da geleira Polar Club. Devido à região de estudo apresentar elevada nebulosidade durante todo o ano e um curto período de verão, adquirir imagens com baixa interferência da atmosfera é um procedimento difícil. Além disso, em maio de 2003 o Corretor de Escaneamento Linear (Scan Line Corrector - SLC) do sensor Enhanced Thematic Mapper Plus (ETM+) do satélite Landsat 7 falhou, a partir de então as imagens aparecem com falhas sistemáticas na forma de faixas sem informação na imagem, o que limita em parte sua utilização.

\subsubsection{Classificação e delineamento da variação na frente da geleira Polar Club}

As imagens foram georreferenciadas a partir de pontos de controle coletados em campo com Global Position System (GPS) e do mapa planialtimétrico da península Potter, com escala 1:10.000 (Lusky et al., 2001). As áreas livres de gelo continental foram extraídas por meio da classificação supervisionada das imagens utilizando a composição de bandas $\mathrm{RGB}=543$, tendo sido utilizado o classificador de Máxima verossimilhança (Maxver) do software IDRISI. Utilizou-se como referência o limite da geleira no ano de 1986, primeiro ano de dados, como base para as análises de variabilidade. A validação da classificação das áreas livres de gelo fez-se utilizando o índice Kappa, que avalia o nível de acerto e de exatidão do classificador (Landis e Koch, 1977).

\subsection{Dados meteorológicos}

A série temporal diária dos dados meteorológicos de temperatura do ar compreende o período de janeiro de 1986 a dezembro de 2011, obtidos pelas Estações Meteorológicas da Base Carlini, Base Frei e Base Bellinghausen.

\subsubsection{Preenchimento dos dados faltantes}

Os dados provenientes da base Carlini apresentaram alguns dias com lacunas nas séries temporais. Estas lacunas foram preenchidas a partir da correlação linear entre dados meteorológicos da base Carlini com os dados da base Frei e/ou da base Bellinghausen. A escolha da utilização dos dados provenientes desta estação deve-se às duas possuírem alta similaridade nas características da paisagem, altitude e proximidade do mar. $\mathrm{O}$ procedimento para o preenchimento das lacunas obedeceu aos seguintes critérios:

a) Interpolação linear: em casos de lacuna em apenas um dia efetuou-se a interpolação linear entre o valor referente ao dia anterior e o valor do dia posterior.

b) Regressão linear: nos casos de lacuna de informações de dois ou mais dias, utilizou-se a equação da reta da regressão entre as estações de Carlini, Frei e/ou Bellinghausen.

Após esta série de procedimentos, todas as lacunas foram preenchidas tornando a base de dados de temperatura atmosférica diária completa e possibilitando a continuidade no processo de padronização.

\subsubsection{Médias Móveis das temperaturas do ar}

Os modelos de médias móveis utilizam como previsão para um determinado período no futuro a média das observações passadas, com base no cálculo a seguir:

$$
X_{t}=\frac{X_{t-1}+X_{t-2}+\cdots+X_{t-n}}{n} .
$$

Em que " $n$ " representa o número de observações (ou janela de observações) incluídas na média " $X_{\mathrm{t}}$ ". Os filtros utilizados representam as janelas de observações, ou seja, 


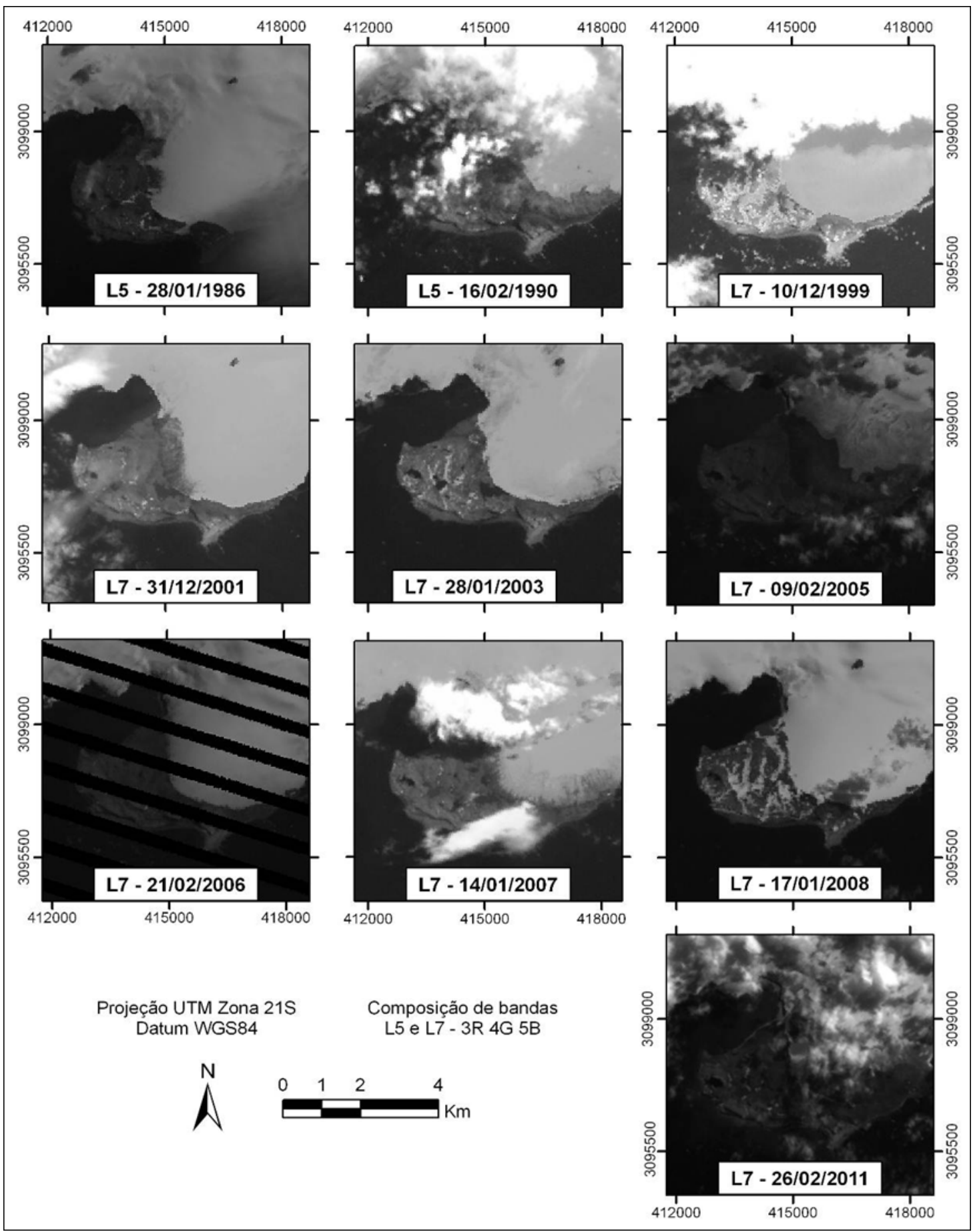

Figura 2 - Acervo de imagens do satélite landsat 5 e 7 em composição RGB das bandas espectrais 3, 4 e 5.

quanto maior a janela, maior o efeito do alisamento na curva. Janelas menores mantem a maior variabilidade da série, por outro lado, quanto maior a janela de observação mais retardado será o comportamento da curva em relação a série de dados.

O Erro Médio Quadrático (EMQ) é a soma das diferenças entre o valor estimado e o valor real dos dados, dividido pelo número de observações:

$$
\mathrm{EMQ}=\sum_{i} \frac{\left(Y_{i}-\widehat{Y}_{i}\right)^{2}}{n}
$$

Em que “" $i$ " sãos os dados reais e “ $i$ " os dados estimados na média móvel, e n o numero de observações. O EMQ é usado para avaliar o quanto o gráfico da média móvel distancia dos dados originais, quanto menor o valor melhor seu ajuste. 


\section{RESULTADOS E DISCUSSÃO}

\subsection{Variações na frente de geleira Polar Club}

O mapa das áreas livres de gelo, contendo os limites da frente de geleira é apresentado na Figura 3. Os remanescentes de neve foram agrupados como área livre de gelo, estando destacado apenas os limites da frente da geleira de cada ano.

Devido à dificuldade de obter-se imagens com baixa interferência atmosférica, os valores obtidos de avanço e recuo podem não ser o máximo para o ano em questão, isto porque algumas imagens não correspondem ao estágio máximo de derretimento relativo a março do ano subsequente. Desta maneira, os valores obtidos neste trabalho são estimativas aproximadas do limite máximo da frente da geleira. Os valores obtidos no índice Kappa calculado para as 10 imagens classificadas foram: 0,$72 ; 0,77 ; 0,85 ; 0,91 ; 0,89$; 0,$94 ; 0,88 ; 0,91 ; 0,84$ e 0,89 para o ano 1986, 1990, 1999, 2001, 2003, 2005, 2006, 2007, 2008 e 2011 respectivamente. Segundo Landis e Koch (1977) valores entre 0,61 e 0,80 são considerados substanciais, e valores entre 0,8 e 1 são satisfatórios.

As taxas de recuo são mais expressivas do que os valores referentes aos avanço da frente da geleira. O maior valor de recuo da frente de geleira sobre a superfície da Península Potter foi registrado em $2007\left(2,47 \mathrm{~km}^{2}\right)$, em contrapartida, o maior valor de avanço foi em 1990 com uma área de $0,33 \mathrm{~km}^{2}$. A área livre de gelo no ano de 1986 era de $6,16 \mathrm{~km}^{2}$, enquanto no ano de $2011 \mathrm{a}$ área livre de gelo atingiu o valor de $8,13 \mathrm{~km}^{2}$. Com base nestes valores, constata-se que ao longo dos últimos 26 anos houve um recuo da frente da geleira Polar Club sobre a superfície de Potter, que resultou no aumento de $1,62 \mathrm{~km}^{2}$, ou

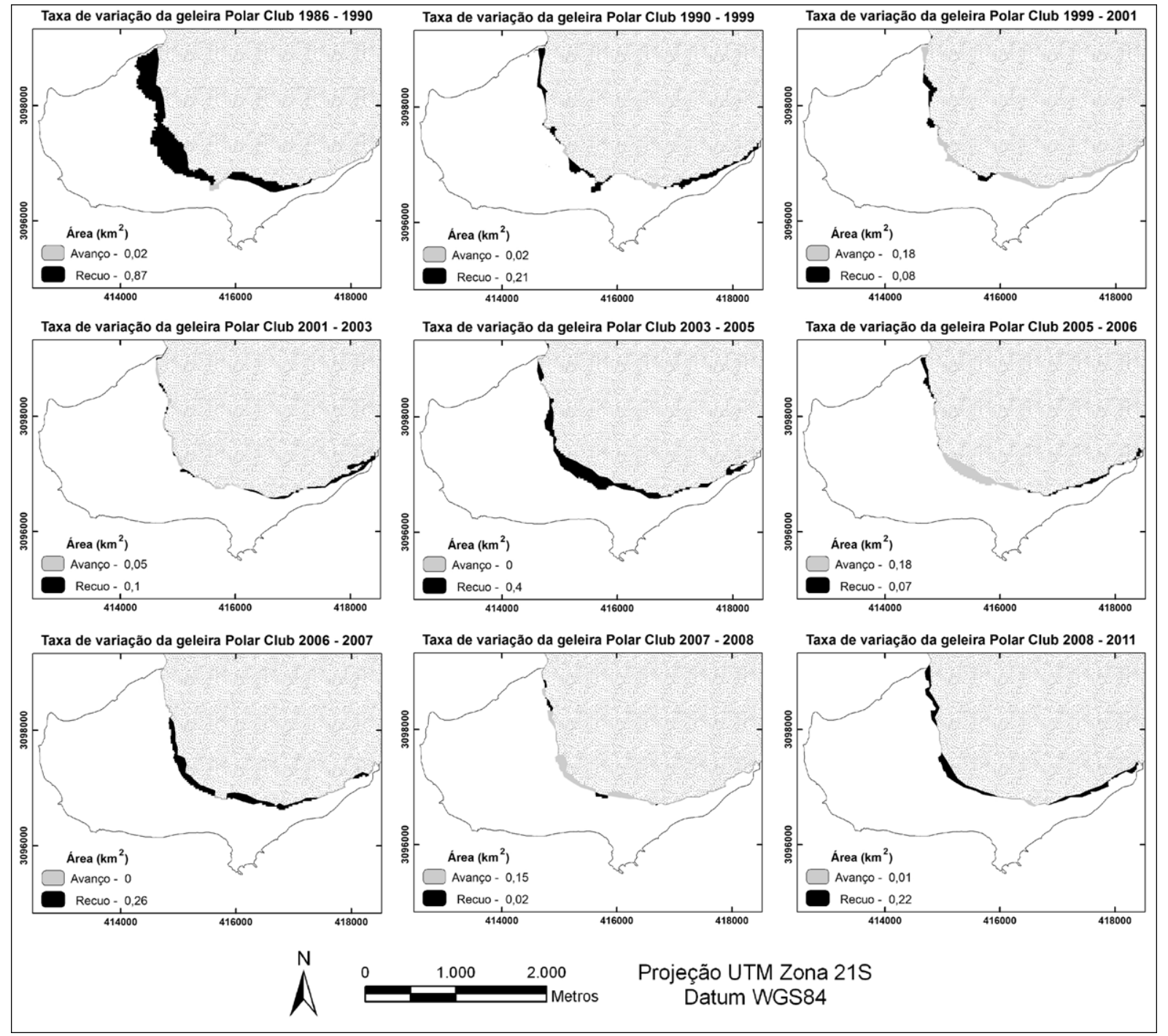

Figura 3 - Taxas de variação da geleira Polar Club durante o período de 1986 a 2008. 
seja, a Península Potter aumentou em 26,53 \% a sua área livre de gelo neste período (Figura 3).

Estes dados corroboram com os apresentados por Braun e Gossmann (2002), que entre os anos de 1956 a 1995 houve uma retração da geleira Polar Club de 10\% em sua área. Outras geleiras como a Dragon, Krak, Pandereski e Wanda apresentaram taxas de retração com valores superiores ao apresentado pela geleira Polar Club neste mesmo período, com destaque para as geleiras Dragon e Krak que tiveram retração de $36 \%$ e $28 \%$ respectivamente de suas áreas (Braun e Gossmann, 2002). Simões et al. (2004) encontraram drásticas reduções em quatro geleiras de pequeno porte na face leste da Península Keller, com redução variando de 44 a 83\% de suas áreas de entre o período de 1970 à 2000.

\subsection{Série temporal de temperaturas do ar para a estação de Carlini}

As temperaturas médias mensais para o período de 1986 a 2011 oscilaram muito com anomalias em vários anos e temperaturas muito distintas. A amplitude atingiu $12,9{ }^{\circ} \mathrm{C}$ para os meses de junho, $10,5^{\circ} \mathrm{C}$ para agosto e $9,3{ }^{\circ} \mathrm{C}$ para setembro, em contrapartida, nos meses de verão a variação foi pequena, $4,4{ }^{\circ} \mathrm{C}$ em dezembro, $2,6^{\circ} \mathrm{C}$ para janeiro e fevereiro com $2,3{ }^{\circ} \mathrm{C}$.

A Tabela 1 apresenta as temperaturas médias organizadas em torno da média e os valores calculados dos decis, quartis e medianas, para qualificar cada mês em relação à série de dados meteorológicos dos 26 anos. O ano de 1989 foi Extremamente Quente (EQ), pois as temperaturas médias do inverno foram muito acima da média, o que elevou a média do ano. Fato semelhante ao ano de 1999, em que os meses de outono até o inverno foram elevados (Moderadamente Quente (ModQ) e EQ) em 2008 foram os períodos da primavera e do verão que elevaram a média do ano para EQ.
Esta série revela ciclos de aproximadamente 10 anos, com temperaturas EQ, intercalados com anos Muito Quente (MQ). Em contrapartida, anos Extremamente Frio (EF) não apresentam ciclos bem definidos, tendo ocorrência apenas em 1986, 1987 e 1990, com anos Muito Frio (MF) em 1992, 1995, 2007 e 2009. A média geral da série ficou em $-1,8^{\circ} \mathrm{C}$, considerada Moderadamente Frio (ModF).

As oscilações mensais na série comprovam a susceptibilidade das temperaturas do ar nessa região às influências das variações das frentes oceânicas e de massas de ar. Essa variabilidade interanual é devida às interações entre atmosfera-gelo-oceano, em que maiores extensões do gelo marinho possuem correlação negativa com a temperatura do ar no inverno. Enquanto a variabilidade das forças de advecção das massas de ar quente, juntamente com anomalias da circulação destas massas à nordeste da Península Antártica, promovem invernos mais quentes (Ferron et al., 2004).

A Figura 5a apresenta o ciclo anual da temperatura média do ar na estação de pesquisa de Carlini. Ocorre maior amplitude das temperaturas no período do inverno, em relação ao verão. Devido a estação estar a poucos metros acima do nível do mar (11 m), predomina a influência marítima, onde as variações na presença de cobertura de gelo marinho contribuem para esta amplitude dos desvios padrões da média nos meses de inverno $\left(12,9,10,5\right.$ e $10^{\circ} \mathrm{C}$ para junho, julho e agosto respectivamente). No verão essa variação é menor, com valores entre 3 e $4{ }^{\circ} \mathrm{C}$.

Considerando as médias dos dados de temperatura por estações do ano (Figura 5b), observa-se maior tendência de aumento para a primavera com acréscimo de $0,0461{ }^{\circ} \mathrm{C}$ ano ${ }^{-1}$, pouco mais que o outono, que apresenta o valor de $0,0468{ }^{\circ} \mathrm{C}$ $a^{-1}$. O verão foi a estação que apresentou o menor valor de aumento na temperatura, com $0,0065{ }^{\circ} \mathrm{C}$ ano ${ }^{-1}$, valor pouco menor do que o do inverno, que obteve $0,02{ }^{\circ} \mathrm{C}$ ano ${ }^{-1}$. Estes valores de acréscimo na temperatura são referentes ao período

Tabela 1 - Quartis e decis e enquadramento das temperaturas médias mensais da série de temporal no período de 1986-2011, da estação meteorológica da Base Carlini, península Potter,.

\begin{tabular}{lccccccccccccc}
\hline & Jan & Fev & Mar & Abr & Mai & Jun & Jul & Ago & Set & Out & Nov & Dez & Média \\
\hline Média & 2,3 & 2,1 & 0,8 & $-1,7$ & $-3,1$ & $-5,5$ & $-6,4$ & $-5,3$ & $-3,7$ & $-1,9$ & $-0,3$ & 1,3 & $-1,8$ \\
EQ & 3,1 & 2,9 & 1,8 & 0,5 & $-0,8$ & $-2,0$ & $-3,2$ & $-2,7$ & $-1,9$ & $-0,3$ & 0,8 & 1,9 & $-0,9$ \\
MQ & 2,7 & 2,6 & 1,4 & $-1,0$ & $-1,4$ & $-3,8$ & $-3,7$ & $-4,0$ & $-2,3$ & $-0,8$ & 0,5 & 1,8 & $-1,1$ \\
ModQ & 2,3 & 2,5 & 0,9 & $-1,4$ & $-2,4$ & -5 & -6 & $-4,6$ & $-3,2$ & $-1,6$ & 0,1 & 1,4 & $-1,7$ \\
N & 2,2 & 2,4 & 0,8 & $-1,5$ & $-2,5$ & $-5,1$ & $-6,1$ & $-4,7$ & $-3,3$ & $-1,7$ & 0,0 & 1,3 & $-1,8$ \\
ModF & 2,1 & 2,3 & 0,7 & $-1,6$ & $-2,6$ & $-5,2$ & $-6,2$ & $-4,8$ & $-3,4$ & $-1,8$ & $-0,1$ & 1,2 & $-1,9$ \\
MF & 1,8 & 1,8 & 0,2 & $-2,4$ & $-4,5$ & $-7,7$ & $-7,8$ & $-6,7$ & $-5,4$ & $-2,8$ & $-0,9$ & 0,9 & $-2,5$ \\
EF & 1,7 & 0,8 & $-0,2$ & $-4,3$ & $-6,5$ & $-8,2$ & $-11,3$ & $-8,3$ & $-6,5$ & $-3,5$ & $-1,5$ & 0,5 & $-3,0$ \\
\hline
\end{tabular}

Temperatura $\left({ }^{\circ} \mathrm{C}\right)$, Extremamente. frio $(\mathrm{EF})=\mathrm{t}<=$ Decil 1; Muito Frio $(\mathrm{MF})=$ Decil $1<\mathrm{t}<=$ Quartil 1; Moderadamente Frio $($ ModF $)=$ Quartil $1<\mathrm{t}<$ Mediana; Normal $(\mathrm{N})=\mathrm{t}=$ Mediana; Moderadamente Quente $(\mathrm{ModQ})=\mathrm{N}<\mathrm{t}<$ Quartil 3; Muito Quente $(\mathrm{MQ})=$ Quartil $3<=\mathrm{t}<$ Decil 9; Extremamente Quente $(\mathrm{EQ})=\mathrm{t}>=$ Decil 9 . 


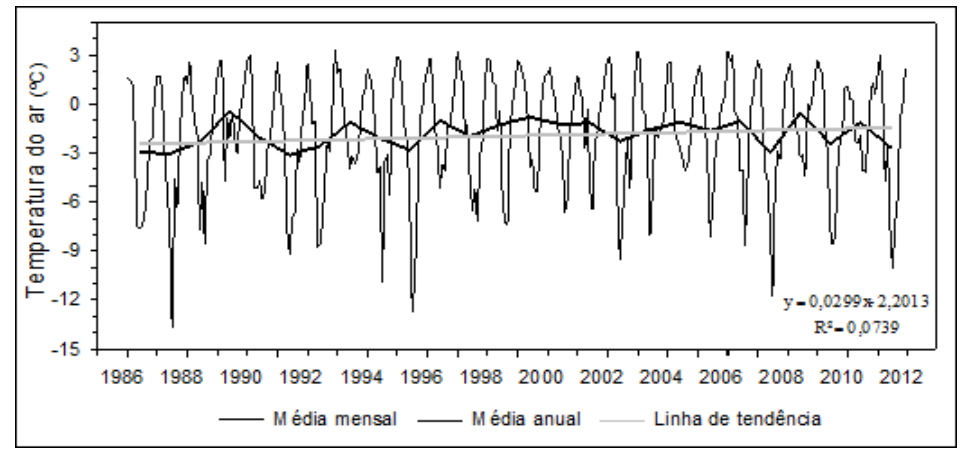

Figura 4 - Temperaturas médias mensais e médias anuais do ar da série de dados da estação meteorológica da Base Carlini (1986 a 2011). Em cinza a linha de tendência das temperaturas médias anuais no período.
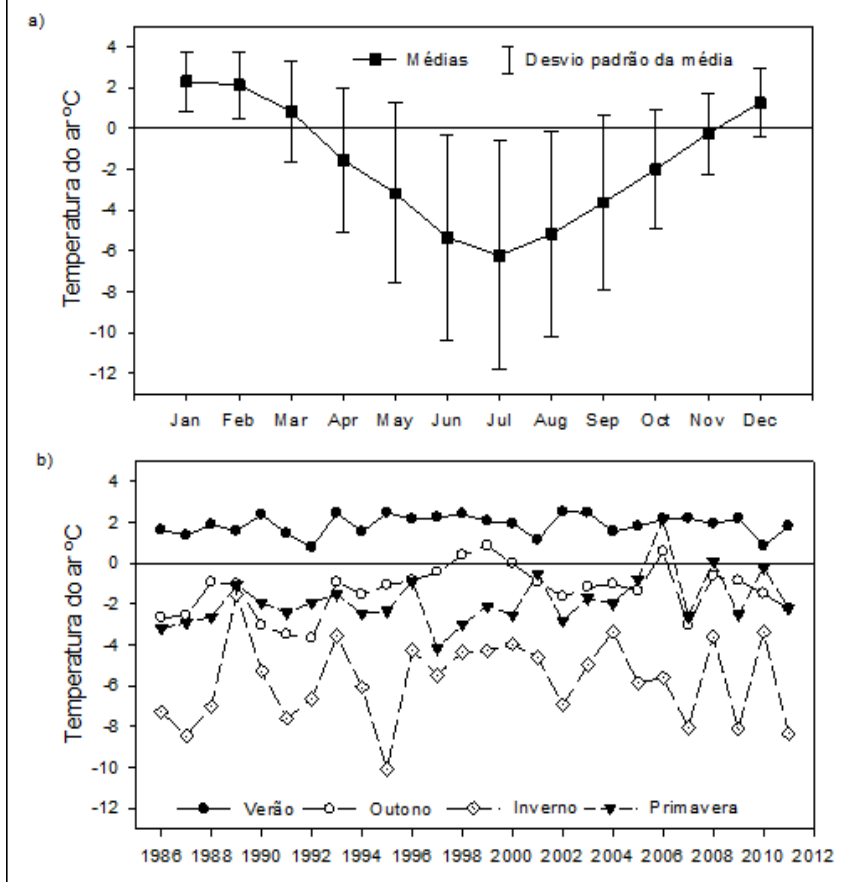

Figura 5 - (a) Distribuição de frequência das temperaturas médias mensais e desvio padrão. (b) Temperaturas médias das quatro estações no período de 1986 a 2011.

estudado, e quando considerado os 26 anos da série de dados atmosféricos analisados foi constatado um incremento na temperatura de $1,17^{\circ} \mathrm{C}$ no outono, $1,15^{\circ} \mathrm{C}$ na primavera, 0,5 ${ }^{\circ} \mathrm{C}$ no inverno e apenas $0,16^{\circ} \mathrm{C}$ no verão.

Pela série de dados (Figura 4) é possível detectar um progressivo aumento das temperaturas médias anuais. Considerando-se os 26 anos da série de dados atmosféricos tem-se uma tendência de $0,04^{\circ} \mathrm{C}$ ano $^{-1}$, o que resulta em um incremento de $1,03{ }^{\circ} \mathrm{C}$ para o período. Estas tendências são maiores que as relatadas por Ferron et al. (2004), que encontraram uma tendência de $0,022^{\circ} \mathrm{C}_{\text {ano }}{ }^{-1}$, com incremento de $1,1^{\circ} \mathrm{C}$ no período de 49 anos (1947 a 1995) para toda a Ilha Rei George. Porém, mantêm-se abaixo da tendência registrada para a Península
Antártica de $2,5^{\circ} \mathrm{C}$ (Turner et al., 2005). Esse incremento na temperatura está conectado com a intensificação da circulação e advecção de ar quente provindo do oeste (Kejna, 2003).

Os ventos exercem grande influência no ecossistema devido à ação abrasiva e ressecamento da superfície, transporte e dispersão de sedimentos, propágulos e acumulação da neve. Os ventos predominantes na estação de Carlini são de oeste e sudoeste (azimutes $270^{\circ}$ e $230^{\circ}$ respectivamente) (Figura 6a), devido à circulação das frentes atmosféricas acompanhando as correntes marinhas do Drake. Esta região é influenciada pela frequente passagem de sistemas ciclônicos que se originam no mar de Bellinghausen e acompanham as correntes oceânicas que seguem para nordeste. No entanto, há ocorrência de ventos fortes acima de $40 \mathrm{~m} / \mathrm{s}$ em todos os quadrantes, principalmente Norte, Nordeste e Sudeste (Figura 6b).

\subsection{Dinâmica da geleira e mudanças climáticas}

A Figura 8 apresenta a série de temperaturas médias anuais atmosféricas de Carlini durante o período de 1986 a 2011, e os valores de áreas livres de gelo obtidos através do mapeamento da variação da frente da geleira Polar Club. A variação interanual na dinâmica da temperatura atmosférica na série considerada, entre 1986 a 1995, apresenta ciclos trienais bem delimitados e com variações bruscas no valor de temperatura. A partir de 1995 o comportamento dos ciclos de variação da temperatura passa a ser assimétrico, porém as variações nos valores de temperatura são menores. Ocorre grande variação entre anos subsequentes, com destaque para os anos de 1989, 1999 e 2008, cujas médias foram as mais elevadas. No curto período de 1998 a 2001, ocorreram seguidos anos com maiores valores nas médias, onde a partir de então, oscilam entre anos mais frios e anos mais quentes. Essas oscilações possuem períodos curtos de 2,4 anos de menor frequência seguidos de períodos secundários de 4 a 5 anos (Figura 7).

Estas variações devem-se possivelmente às alterações em macro clima, das massas polares e correntes marítimas que 

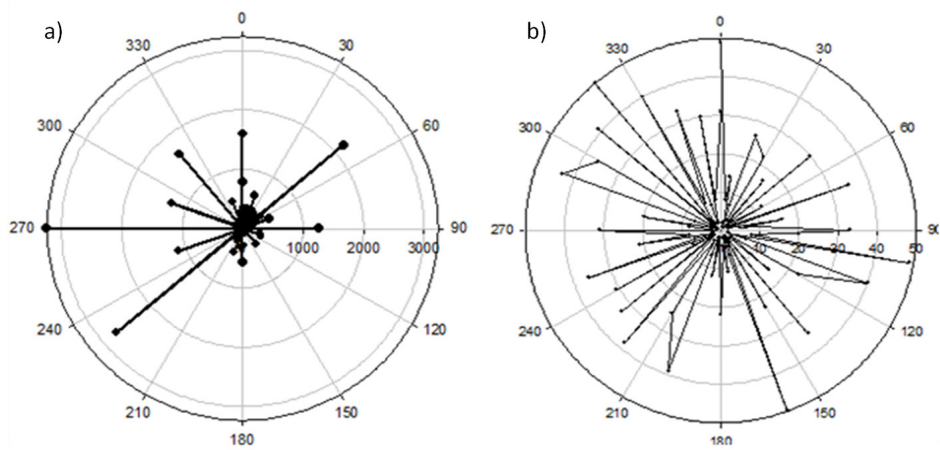

Figura 6 - (a) Anemograma climatológico da estação Carlini. (b) Direção predominante do vento (número de ocorrências) média das velocidades máximas diárias $(\mathrm{m} / \mathrm{s})$.

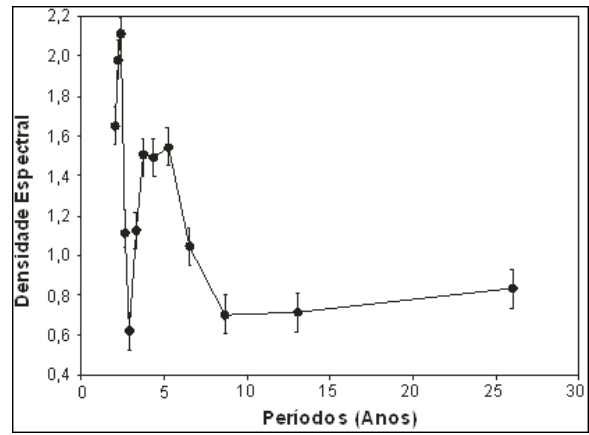

Figura 7 - Resultado da análise espectral de temperatura média anual da série de dados da estação climática de Carlini, com valores de limites de confiança.

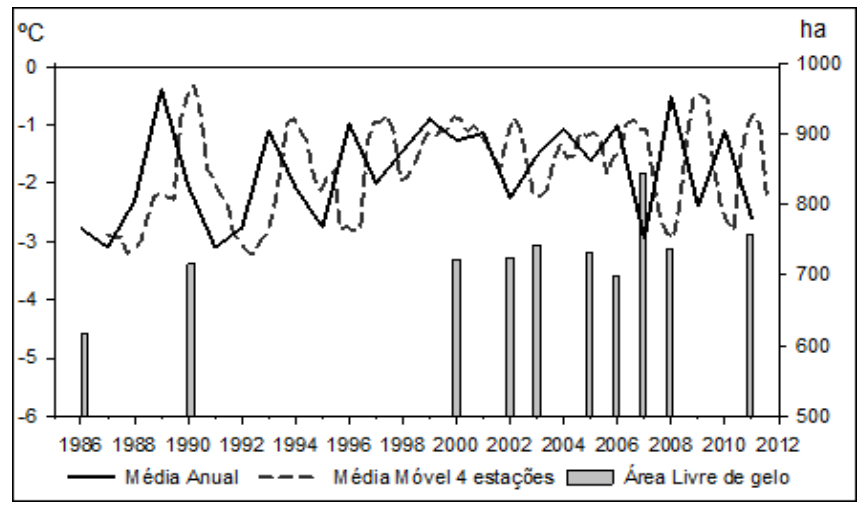

Figura 8 - Média anual e médias móveis das temperaturas do ar na superfície e áreas livres de gelo da Península Potter durante o período de 1986 a 2011.

afetam diretamente o clima desta região. Ferron et al. (2004) encontraram grande variabilidade interanual ao analisar os dados entre 1947 e 1995, em que identificaram ciclo dominantes de 5,3 anos e secundários de 9,6 anos. Estes ciclos são caracterizados por anos mais frios seguidos por períodos mais quentes. Em Potter, esta tendência é observada, com anos frios intercalados por anos mais quentes (Figura 8).
Os resultados dos EMQ apresentou média móvel para quatro estações com 9,04, enquanto que as médias de duas e três estações os valores foram de 20,05 e 14,59. O melhor ajuste é apresentado na Figura 8, com a média móvel de 4 estações consecutivas, a variação na área livre de gelo e o gráfico da temperatura média anual. Nota-se o retardo de um ano para a resposta no recuo da frente de geleira. No período de 1986 a 1990 ocorreu um grande incremento nas temperaturas do ar, juntamente com aumento das áreas livres de gelo. Um segundo evento pode ser percebido nos anos de 2007 a 2008, onde com atraso de um ano no aumento das temperaturas, a frente de geleira teve um grande retrocesso, enquanto no ano seguinte voltou a expandir, acompanhado pelo gráfico das medias móveis das quatro estações.

O processo de retração da geleira Polar Club teve início no Holoceno, resultando na transformação da paisagem da península e surgimento dos lagos (Birkenmajer, 1998; del Valle et al., 2004) (Figura 9). No entanto, nas últimas décadas este recuo pode ter sido potencializado, possivelmente pelas rápidas alterações climáticas ocorridas nessa região (Ferron et al., 2004; Turner et al., 2005; Chwedorzewska, 2009).

O comportamento da variação da frente de geleira possui uma complexa relação com diferentes elementos da paisagem, como espessura da cobertura de gelo, temperatura da água, relevo e forças internas. Segundo Braun e Gossmann (2002) as condições meteorológicas e as mudanças na circulação atmosférica são elementos preponderantes na modificação dos sistemas de geleiras da Ilha Rei George, com a Dragon, Krak, Pandereski e Wanda. Conforme constataram Braun e Gossmann (2002), as geleiras localizadas nas Ilhas Shetland do Sul ao longo do período observado não apresentaram padrões semelhantes de reação, algumas recuaram muito em comparação a outras, havendo até a ocorrência de geleiras que se mantiveram estáveis. Este processo de avanço e recuo espacialmente localizado, possivelmente resulta da acomodação de condições dinâmicas da geleira, juntamente com a recarga por precipitação de neve. 


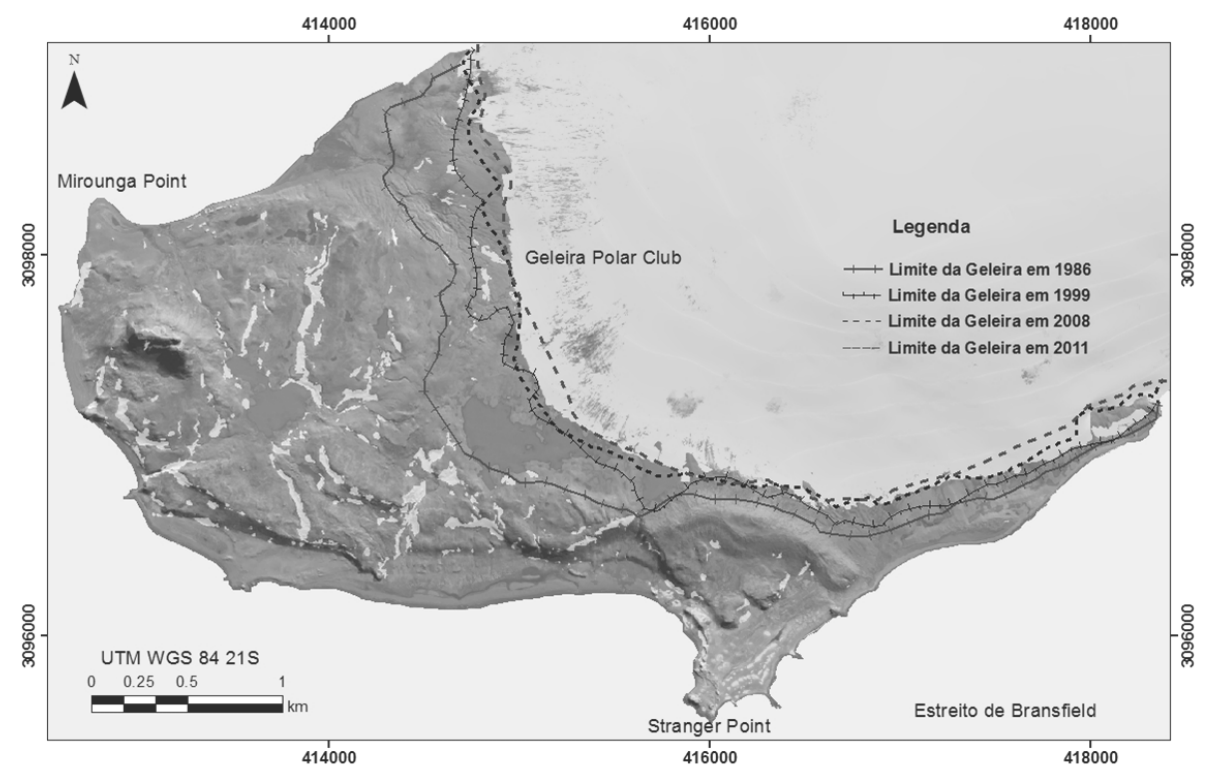

Figura 9 - Limites da frende da geleira Polar Club nos anos de 1986, 1999, 2008 e 2011 sobre a imagem Quickbird 2 de 2007 da Península Potter.

Não é possível apontar um único elemento como sendo o causador destes processos de retração das geleiras na Ilha Rei George, entretanto, há fortes indícios de que estas dinâmicas das geleiras foram iniciadas devido às mudanças climáticas (Braun e Gossmann, 2002) o que corrobora Park et al. (1998) e Kejna et al. (1998) que atribuem o recuo das geleiras ao aumento da temperatura média do ar da região. Para Kejna (2003) esses processos são de decorrência natural, devido ao aquecimento marinho dessa região. No entanto, Kejna (2003) encontrou tendências de incrementos de temperaturas atmosféricas diferentes para outras partes da Antártica, enquanto a Península Antártica apresenta tendências positivas, o continente vem resfriando a cada ano, o que pode compensar e manter o sistema climático atual em todo o continente antártico.

\section{CONCLUSÕES}

Com base nos valores obtidos, constata-se que ao longo dos últimos 26 anos ocorreu o recuo da frente da geleira Polar Club. Considerando-se a série de dados de temperatura atmosférica entre 1986 e 2011 coletadas na estação de pesquisa de Carlini, expõe tendência de aumento de $0,04{ }^{\circ} \mathrm{C}$ por ano, resultando no incremento de $1,03{ }^{\circ} \mathrm{C}$ para o período. Neste mesmo período ocorreu um aumento de $1,63 \mathrm{~km} 2$ de área livre de gelo, ou seja, a Península Potter aumentou em 26,53 $\%$ a sua área livre de gelo neste. A influência das temperaturas atmosféricas no recuo da geleira demonstra retardamento de cerca de um ano.

Apesar das evidências do aumento das temperaturas médias do ar na região nas últimas décadas, a retração da frente de geleira Polar Club pode estar associada à reacomodações dinâmicas da calota de gelo em toda Ilha Rei George, às alterações nas taxas de precipitação e às condições climáticas. Desta maneira, para a Península Potter não se pode atribuir como causa das variações da geleira Polar Club somente a temperatura atmosférica.

Em futuros trabalhos serão estudadas outras áreas nas Ilhas Shetland do Sul e da Península Antártica, para relacionar as recentes alterações climáticas com a dinâmica das frentes de geleiras e paisagem nestas regiões.

\section{REFERÊNCIAS}

ANDRADE, A. M. de; ARIGONY-NETO, J.; POELKING, E. L.; SCHAEFER, C. E. G. R.; BREMER, U. F.; FERNANDES FILHO, E. I. Avaliação da influência da radiação solar na distribuição superficial da vegetação na península Potter, Antártica Marítima. Revista Brasileira de Cartografia, v. 21, n. 66, p. 14-26, 2014.

ARIGONY NETO, J.; BREMER, U. F.; SIMÕES, J. C. Variações nas frentes de gelo da Enseada Martel, illha Rei GeorgeIlha Rei George, Antártica, entre 1956 e 2000. In: SIMPÓSIO BRASILEIRO DE SENSORIAMENTO REMOTO, 10, 2001, Foz do Iguaçu. Anais... Foz do Iguaçu: INPE, 2001. p. 709-711.

BIRKENMAJER, K. Geology of Volcanic Rocks (Upper Cretaceous-Lower Tertiary) at Potter Peninsula, King George Island (South Shetland Islands, West Antarctica. Bulletin of the Polish Academy of Sciences. Earth Sciences, v. 46-2, p. 147-155, 1998. 
BRAUN, M.; GOSSMANN, H. Glacial changes in the areas of Admiralty Bay and Potter Cove, King Geoge Island, maritime Antarctica. In: BEYER, L.; BÖLTER, M. (Org.). Geoecology of Antarctic ice-free coastal landscapes. Berlin: Springer-Verlag. 2002. P. 75-89.

BRAUN, M.; SIMÕES, J. C.; VOGT, S.; BREMER, U. F.; SAURER, H.; AQUINO, F. E. A new satellite image map of King George Island (South Shetland Islands, Antarctica). Polarforschung, v. 71, p. 47-48. 2001.

BREMER, U. F.; ARIGONY NETO, J.; SIMÕES, J. C. Teledetecção de mudanças nas bacias de drenagem do gelo da ilha Rei GeorgeIlha Rei George, Shetlands do Sul, Antártica, entre 1956 e 2000. Pesquisa Antártica Brasileira, n. 4, p. 37-48. 2004.

CHWEDORZEWSKA, K. J. Terrestrial Antarctic ecosystems in the changing world: an overview. Polish Polar Research, n. 30, p. 263-276. 2009.

CONVEY, P. Antarctic Terrestrial Ecosystems: Responses to Environmental Change. Polarforschung, 75 (2-3), p. 101111. 2006.

DEL VALLE, R. A.; TATUR, A.; LUSKY, J. C.; GOMEZ IZQUIERDO, D. R. Cambios morfológicos recientes en lagos de la Península Potter, Isla 25 de Mayo, Islas Shetland del Sur, Antártida. Revista de la Asociación Geológica Argentina, n. 59, p. 443-50. 2004.

FERRON, F. A.; SIMÕES, J. C.; AQUINO, F. E.; SETZER, A. W. Air temperature time series for King George Island, Antarctica. Pesquisa Antártica Brasileira, n. 4, p. 155169. 2004.

HOUGHTON, J. T.; DING, Y.; GRIGGS, D. J.; NOGUER, M.; VAN DER LINDEN, P. J.; XIAOSU, D. (Org) Climate Change 2001: The Scientific Basis: Contributions of Working Group In: TO THE THIRD ASSESSMENT REPORT OF THE INTERGOVERNMENTAL PANEL ON CLIMATE CHANGE. 1 Anais... Cambridge: University Press, 881 p, 2001.

KEJNA, M. Trends of air temperature of the Antarctic during the period 1958-2000. Polish Polar Research, v. 24, n. 2, p. 99-126, 2003.

KEJNA, M.; LÁSKA, K.; CAPUTA, Z. Recession of Ecology Glacier (King George Island) in the period 1961-1996. In: POLISH POLAR STUDIES 25TH INTERNACIONAL SYMPOSIUM, 1998, Anais... Warszawa: Institute of Geophysics of the Polish Academy of Sciences, 1998. p. 121-128.

KÖPPEN, W. Climatologia: con un studio de los climas de la tierra. Fondo de Cultura Economica: México. 479 p. 1948.
LANDIS, J. R.; KOCH, G. G. The meansurement of observer agreement for categorical data. Biometrics. v. 33, n. 1, 1977.

LUSKY, J. C.; VALLVERDÚ, R. A.; GÓMEZ IZQUIERDO D. R.; del VALLE R. A.; FELSKE, H. Mapa digital de peninsula Potter isla 25 de Mayo (King George Island). Instituto Antártico Argentino. 2001.

NATIONAL RESEARCH COUNCIL. Reconciling Observations of Global Temperature Change. Washington, DC: National Academy Press. 2000.

PARK, B. K.; CHANG, S. K.; YOON, H. I.; CHUNG, H. Recent retreat of ice cliffs, King George Island, South Shetland Islands, Antarctic Peninsula. Ann Glaciol. n. 27, p. 267-274, 1998.

SETZER, A.; OLIVEIRA, M. R.; FRANCELINO, M. R.; SCHAEFER, C. E.; COSTA, L. M.; BREMER, U. F. Regime Climático na Baía do Almirantado: Relações com o Ecossistema Terrestre. In: SCHAEFER, C. N.; FRANCELINO, M. R.; SIMAS, F. N. B.; ALBUQUERQUE FILHO, M. R. de (Org.). Ecossistemas costeiros e monitoramento ambiental da Antártica marítima: Baía do Almirantado, IiIha Rei George. Viçosa: NEPUT, 2004, p. 47-58.

SIMÕES, J. C.; DANI, N.; BREMER, U. F.; AQUINO, F. E.; ARIGONY-NETO, J. Small cirque glaciers retreat on Keller Peninsula, Admiralty Bay, King George Island, Antarctica. Pesquisa Antártica Brasileira, n. 4, p. 49-56, 2004.

SLAYMAKER, O.; KELLY, R. The Cryosphere and Global Environmental Change. Blackwell Publishing. p. 261, 2007. TURNER, J.; COLWELL, S. R.; MARSHALL, G. J.; LACHLAN-COPE, T. A.; CARLETON, A. M.; JONES, P. D.; LAGUN, V.; REID, P. A.; IAGOVKINA, S. Antarctic climate change during the last 50 years. International Journal of Climatology, v. 3, n. 25, p. 279-294, 2005.

USGS. United States Geological Survey. Disponível em: $<$ http://www.usgs.gov>. Acesso em: 20 jan. 2010.

VAUGHAN, D. G.; MARSHALL, G. J.; CONNOLLEY, W. M.; KING, J. C.; MULVANEY, R. C. Evil in the Detail. Science, v. 293, n. 5536, 2001.

VIEIRA, G.; BOCKHEIM, J.; GUGLIELMIN, M.; BALKS, M.; ABRAMOV, A. A.; BOELHOUWERS, J.; CANNONE, N.; GANZERT, L.; GILICHINSKY, D. A.; GORYACHKIN, S.; LÓPEZ-MARTÍNEZ, J.; MEIKLEJOHN, I.; RAFFI, R.; RAMOS, M.; SCHAEFER, C.; SERRANO, E.; SIMAS, F.; SLETTEN, R.; WAGNER, D. Thermal state of permafrost and active-layer monitoring in the antarctic: Advances during the international polar year 2007-2009. Permafrost and Periglacial Processes, n. 21, p. 182-197, 2010. 